\title{
Antimutagenic effects of aqueous fraction of Myristica fragrans (Houtt.) leaves on Salmonella typhimurium and Mus musculus
}

\author{
Akeem Akinboro1, $3 \otimes$, Kamaruzaman Bin Mohamed', Mohd Zaini Asmawi ${ }^{2}$ and \\ Taofeek A. Yekeen ${ }^{3}$ \\ 1School of Biological Sciences, Universiti Sains Malaysia, 11800, Pulau Pinang, Malaysia; ${ }^{2}$ School of Pharmaceutical Sciences, Universiti Sains \\ Malaysia, 11800, Pula Pinang, Malaysia; ${ }^{3}$ Department of Pure and Applied Biology, Ladoke Akintola University of Technology, P.M.B.4000, Oyo \\ State, Nigeria
}

\begin{abstract}
Natural plant extracts offer a promising hope in the prevention/treatment of cancer arising from genetic mutations. This study evaluated in vitro and in vivo mutagenic and antimutagenic effects of aqueous fraction of Myristica fragrans (AFMF) leaves on TA100 strain of Salmonella typhimurium and Mus musculus (Male Swiss albino mice), respectively. The antioxidant activity of AFMF against 2,2-diphenyl-1-picrylhydrazyl (DPPH), total phenolic and flavonoid contents were determined, followed by its phytochemical elucidation using the Ultra Performance Liquid Chromatography technique (UPLC). The mutagenicity of AFMF at 4, 20, 50, 100, 200, 500, and $1000 \mu \mathrm{g} /$ well was $<2.0$ in $S$. typhimurium and the induced micronucleated polychromatic and normochromatic erythrocytes at 500, 1000, 2000, and $4000 \mathrm{mg} / \mathrm{kg}$ were not significantly different from the negative control $(p \geq 0.05)$. The mutagenic activity of benzo[a]pyrene and cyclophosphamide was significantly suppressed above $50.0 \%$ throughout the tested concentrations. Fifty percent of the free radicals from DPPH were scavenged by AFMF at $0.11 \mathrm{mg} / \mathrm{ml}$. Total phenolic and flavonoid contents of AFMF were $51.0 \mathrm{mg} \mathrm{GAE} / \mathrm{g}$ and $27 \mathrm{mg} \mathrm{QE} / \mathrm{g}$, respectively. Rutin was elucidated by the UPLC technique, and thereby suspected to be the phytochemical responsible for the observed antimutagenic activity. Thus far, AFMF seems to contain a promising chemotherapeutic agent for the prevention of genetic damage that is crucial for cancer development.
\end{abstract}

Key words: benzo[a]pyrene, chromosome, aberrations, cyclophosphamide, micronucleus, Myristica fragrans, Salmonella typhimurium

Received: 19 April, 2014; revised: 24 October, 2014; accepted: 07 November, 2014; available on-line: 16 December, 2014

\section{INTRODUCTION}

Cancer is the second leading cause of human death worldwide despite many therapeutic measures being taken to control it. The use of natural products as new chemopreventive agents stands promising in reducing the number of deaths being recorded annually from cancer. Antimutagenic and anticarcinogenic agents offer the most effective procedure for the prevention of cancer and other genetic diseases in humans, as inhibition of the mandatory initiation stage of carcinogenesis is an important antidote to emergence of cancer (Ferguson, 1994). Occurrence of cancer and degenerative diseases has been connected with generation of excess reactive oxygen species (ROS), inducing cell damage due to imbalance between antioxdants and oxidants ( $\mathrm{Su}$ et al., 2007; Chatterjee et al., 2007).

Phenolic phytochemical compounds, possessing ability to remove free radicals, chelate metallic catalysts, activate antioxidant enzymes and inhibiting oxidases are given a considerable attention because of their diverse biological and beneficial health effects (Oh et al., 2008). Myristica fragrans (Houtt.), a tropical evergreen plant with aromas, gains its popularity among the plants that are being used as spices and in traditional medicines because of its immensely diverse phytochemical constituents (Iyer et al., 2009; Nguyen et al., 2010). Previous studies on evaluation of $M$. fragrans extracts for different activities such as antimicrobial, anxiogenic, antioxidant, cytotoxicity, hypolipidemic and anticarciogenic effects had employed the fruit, dried seed (nutmeg), aril (mace), and bark of this plant (Sulaiman and Ooi, 2011; Piaru et al., 2011). No known reports had ever considered the leaves of $M$. fragrans for similar investigation before our previously reported remarkable DPPH free radical scavenging activity and suppression of cyclophosphamide-induced chromosomal aberrations by the fruit juice and leaf extract of $M$. fragrans in the Allium cepa test (Akinboro et al., 2011a; Akiboro et al., 2011b). The results of our preliminary investigation on mutagenic and antimutagenic activities of methanol leaf extract of $M$. fragrans using in vitro and in vivo genetic models revealed the presence of phytochemical(s) that could be employed for the development of anticancer therapeutics (Akinboro et al., 2012).

However, the present study sought to evaluate antimutagenic activity of aqueous fraction of methanol leaf extract of Myristica fragrans and elucidate its suspected antimutagenic constituent without ignoring the possibility of it being mutagenic in the selected genetic assays for this study.

e-mail: akinboroa@yahoo.com; aakinboro@lautech.edu.ng Abbreviations: AFMF, aqueous fraction of Myristica fragrans; AFB1, aflatoxin $\mathrm{B} 1$; $A A F$, acetamido-fluorene; $B H A$, butylated hydroxyl anisole; BHT, butylated hydroxyl toluene; $\mathrm{B}[\mathrm{a}] \mathrm{P}$, benzo[a]pyrene; CP, cyclophosphamide; DPPH, 2,2,-diphenyl-1-picryl hydrazyl; DNA, deoxyribonucleic acid; FBS, fetal bovin serum; GAE, gallic acid equivalent; HPLC, high performance liquid chromatography; MNPCEs, micronucleated polychromatic erythrocytes; MNNCE, micronucleated normochromatic erythrocytes; NCE, normochromatic erythrocytes; OECD, organization for economic cooperation and development; PCE, polychromatic erythrocytes; PDA, photodiode array; SR, spontaneous revertant; UPLC, ultra performance liquid chromatography; USM, university sain Malaysia 


\section{MATERIALS AND METHODS}

Chemicals. Recommended standard chemical reagents for this study were purchased from Sigma Aldrich, Munich, Germany, while the technical grade chemicals were collected at the chemical stores of Schools of Biological and Pharmaceutical Sciences, Universiti Sains Malaysia (USM).

Salmonella typhimurium strain (TA100). The histidine-requiring strain of Salmonella typhimurium TA100 (frozen) as part of the strains recommended by the OECD guidelines (OECD, 1997) was kindly supplied by Dr. Sedigheh Mehrabian, Faculty of Sciences, University of Tehran, Tehran, Iran.

Animals. The use of mice was approved in the letter with reference number PPSG/07 (A) /044/ issued by the animal ethics committee, USM. This was in line with the internationally accepted guidelines for the treatment of animals in behavioral research and teaching (Sherwin, 2006). Mice were acclimatized to the conditions (temperature, $29 \pm 1{ }^{\circ} \mathrm{C}$; humidity, $70 \pm 10 \%$; 12-hour light-dark cycle) in the transit room in the School of Pharmaceutical Sciences, USM, for one week before the commencement of experiment. They were kept inside plastic cages with wood shavings for bedding, and supplied with standard chow and water ad libitum.

Extraction and fractionation of plant material. The plant sample was identified at the herbarium unit of the School of Biological Science where voucher specimen number 11081 was assigned. Fresh leaves were plucked, rinsed with tap water and oven dried at $40^{\circ} \mathrm{C}$ for 24 hours. The dried leaves were ground into fine powder and extracted with analytical grade methanol in ratio 1:10 (powder:solvent, w/v) (Akinboro et al., 2012). The methanol extract was concentrated in a rotary evaporator at $40^{\circ} \mathrm{C}$, followed by freeze drying and kept at $4^{\circ} \mathrm{C}$ for fractionation.

The freeze dried methanol extract was serially fractionated $(1: 10, \mathrm{w} / \mathrm{v}$, extract:solvent ratio) to obtain petroleum ether, chloroform, ethyl acetate, $n$-butanol and aqueous fractions as reported (William \& Douglas, 2005). The aqueous fraction was filtered through layers of muslin cloth, concentrated in a rotary evaporator at $40^{\circ} \mathrm{C}$, and then freeze dried before it was kept at $4^{\circ} \mathrm{C}$ for experimentations.

In vitro mutagenicity and antimutagenicity (Ames test). $80 \mu \mathrm{L}$ of an overnight bacterial culture of TA100 were added to $1.6 \mathrm{~mL}$ top agar, followed by addition of $80 \mu \mathrm{L}$ of AFMF alone at 4, 20, 50, 100, 200, 500 and $1,000 \mu \mathrm{g} /$ well concentrations. Thereafter, 400 $\mu \mathrm{L}$ of S9 mix was added to the mixture in a test tube for the mutagenic test (Flamand et al., 2001). Antimutagenic screening of AFMF was similar to the mutagenic test but with addition of $20 \mu \mathrm{L}$ of benzo[a]pyrene to the final mixture. The mixture was homogenized, after which $540 \mu \mathrm{L}$ of the resulting mixture was poured, in triplicates per concentration, into six-well plates containing $5 \mathrm{~mL}$ of the glucose minimal agar. This was allowed to solidify, before incubation at $37^{\circ} \mathrm{C}$ for 72 hours (Mortelmans and Zeiger, 2000). Distilled water and benzo[a] pyrene $(0.1 \mu \mathrm{g} /$ well $)$ served as the negative and positive controls, respectively. Thereafter, the number of histidine-independent revertants obtained at each concentration was counted manually. The results were expressed as the mean of triplicate experiments per concentration. The mutagenicity ratio $(R)$ was calculated as the ratio between the number of revertants at each concentration and the revertants induced by the control solvent. The aqueous fraction of $M$. fragrans was considered mutagenic if the mutagenicity ratio was $(R) \geq 2$ at any concentration less than or equal to $100 \mu \mathrm{g} /$ well for the tester strain TA 100 (Loh et al., 2009). The antimutagenic efficacy of AFMF was calculated as previously reported (Negi et al., 2003) using the formula:

$\%$ inhibition of $\mathrm{B}[\mathrm{a}] \mathrm{P}$-induced mutagenicity $=\frac{(\mathbf{R} 1-\mathrm{SR})-(\mathbf{R Z}-\mathbf{S R})}{(\mathbb{R} 1-\mathrm{SR})} \times 100$ where R1 is the number of revertants recorded with $\mathrm{B}[\mathrm{a}]$ $\mathrm{P}$ alone, $\mathrm{R} 2$ is the number of revertants recorded with the mixture of AFMF and B[a]P, and SR is the number of spontaneous revertants in the negative control.

However, the antimutagenic efficacy of AFMF was considered strong if the percentage of inhibition of mutagenicity of $\mathrm{B}[\mathrm{a}] \mathrm{P}$ was $40 \%, 25-40 \%$ for moderate, and less than $25 \%$ for weak or absence of antimutagenic effects.

In vivo mutagenicity and antimutagenicity (Bone marrow micronucleus test). In the micronucleus test, mutagenic evaluation was carried out with four male mice (8-week old), per dose level. They were orally administered a solution of the AFMF alone at $500 \mathrm{mg} / \mathrm{kg}, 1000$ $\mathrm{mg} / \mathrm{kg}, 2000 \mathrm{mg} / \mathrm{kg}$ and $4000 \mathrm{mg} / \mathrm{kg}(0.1 \mathrm{ml} / 10 \mathrm{~g} \mathrm{v} / \mathrm{w}$, volume:body weight). The antimutagenic test was carried out by orally administering cyclophosphamide (CP) at $50 \mathrm{mg} / \mathrm{kg}(0.1 \mathrm{ml} / 10 \mathrm{~g} \mathrm{v} / \mathrm{w}$, volume/body weight) to the male mice 5 minutes before the administration of AFMF. Distilled water and CP (50 mg/kg, w/v) served as the negative and positive controls, respectively ( $\mathrm{da}$ Silva et al., 2002). After $24 \mathrm{~h}$, the mice were sacrificed after inhaling diethyl-ether for 1 minute. Both femurs were dissected and bone marrow was flushed into test tubes containing fetal bovine serum (FBS). The mixture was centrifuged at $300 \times g$ for 10 minutes in an Eppendorf centrifuge (5403; Geratebau Eppendorf $\mathrm{GmbH}$, Engelsdorf, Germany) set at $0^{\circ} \mathrm{C}$. Smear of cell pellets was prepared on glass slides and treated as previously reported (Krishna and Hayashi, 2000). Total of 2000 cells, per mouse, were observed for micronucleated polychromatic and normochromatic erythrocytes (MNPCEs and MNNCEs) using $100 \times$ oil immersion objective lens in a compound light microscope (Nikon E400). To assess bone marrow cytotoxicity, 200 erythrocytes were evaluated per mouse for the proportion of polychromatic erythrocytes (PCEs) in the total erythrocytes counted. The antimutagenic potency of AFMF against the mutagenicity of $\mathrm{CP}$ was calculated as reported (Furtado et al., 2008), but with a slight modification.

$$
\begin{aligned}
& \text { Clastogenic effects }(\%)=\frac{\text { Number of MNPCE } x+\text { Number of MNXCE } \varepsilon}{\text { Total mumber of founted erythrocytez }} \times 100 \\
& \text { Cytotoxic effects }(\%)=\frac{\text { number ofpcs: }}{\text { Total numbev of } 20 \text { ounted erythwocyta } \Sigma} \times 100 \\
& \% \text { Reduction of CP-induced } \mathrm{MN}=\frac{A-\mathbb{B}}{A-\varepsilon} \times 100
\end{aligned}
$$

where 'A' represents frequency of MNPCEs and MNNCEs induced by $\mathrm{CP}$, 'B' represents frequency of $\mathrm{MN}$ PCEs and MNNCEs induced by the mixture of AFMF and $\mathrm{CP}$, 'C' represents frequency of MNPCEs and MNNCEs induced by distilled water.

\section{DPPH free radical scavenging test. The AFMF} was tested for its scavenging activity against DPPH (2,2-diphenyl-1-picrylhydrazyl) following the described methods (Rosidah et al., 2008; Ham et al., 2009). Briefly, $2 \mathrm{mg} / \mathrm{ml}$ AFMF was dissolved in HPLC grade methanol, while butylated hydroxylanisole (BHA) and butylated hydroxyltoluene (BHT) were the reference standards prepared at $1 \mathrm{mg} / \mathrm{mL}$. DPPH solution $(0.1 \mathrm{mM})$ was prepared and dissolved in $100 \mathrm{ml}$ of HPLC grade methanol. In each of the 96-well microplate, the reaction per- 
formed in triplicate contained $100 \mu \mathrm{L}$ of each of AFMF, the reference standard or HPLC methanol, mixed with $200 \mu \mathrm{L}$ of $0.1 \mathrm{mM}$ DPPH solution. The microwell plate was incubated at room temperature for 30 minutes after which the reaction was measured at $517 \mathrm{~nm}$ (wavelength) in a microplate reader (PowerWave $\times$ TM). The $\mathrm{IC}_{50}$ values were interpolated on the graph of percentage scavenging activity against concentration (Gulcin, 2009).

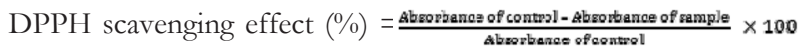

Total phenolic contents. The total phenolic content in AFMF was determined but with some modifications of the Folin-Ciocalteu's method using the 96-well microplate assay (Sulaiman et al., 2011). The AFMF, at 1 $\mathrm{mg} / \mathrm{ml}$, was dissolved in HPLC grade methanol-distilled water $(5: 5, \mathrm{v} / \mathrm{v})$ in a test tube. Gallic acid, at $1 \mathrm{mg} / \mathrm{ml}$, was prepared and further diluted by two folds to obtain $0.004-0.5 \mathrm{mg} / \mathrm{ml}$ concentration range to plot the standard calibration curve. Aliquot of $20 \mu \mathrm{l}$ AFMF and Gallic acid, in triplicate, was added with $40 \mu \mathrm{l}$ of Folin Ciocalteu reagent in a 96 microwell plate, and left for 10 minutes at room temperature $\left(27 \pm 1^{\circ} \mathrm{C}\right)$. Thereafter, 75 $\mu \mathrm{l}$ of $20 \%(\mathrm{w} / \mathrm{v})$ sodium carbonate solution and $150 \mu \mathrm{l}$ distilled water were added to the mixture and then incubated at $40^{\circ} \mathrm{C}$ for 30 minutes (Jayaprakasha et al., 2007). Reaction of the mixture was measured at $765 \mathrm{~nm}$ against the blank using a microplate reader (PowerWave $\times$ TM). The phenolic content was expressed as milligram of Gallic acid equivalents (GAE) per gram of AFMF (Loh et al., 2009).

Total flavonoids. AFMF and quercetin were dissolved separately in HPLC grade methanol at $1 \mathrm{mg} / \mathrm{ml}$. The initial solution of quercetin was serially diluted (two folds) to lower concentrations. In each well of a 96-microwell plate, $35 \mu \mathrm{l} \mathrm{AFMF}$ aliquot and quercetin, in triplicate, was separately mixed with $75 \mu \mathrm{l}$ of $95 \%$ ethanol, followed by addition of $20 \mu \mathrm{l}$ freshly prepared $10 \%$ aluminum chloride, $10 \mu \mathrm{l}$ of $1.0 \mathrm{M}$ potassium acetate and $140 \mu \mathrm{l}$ distilled water (Sulaiman et al., 2011; Boubaker et al., 2010).

A blank reaction contained all reagents except Aluminum chloride and Potassium acetate. The reaction mixture was incubated at room temperature $\left(27 \pm 1^{\circ} \mathrm{C}\right)$ for 40 minutes, after which reaction of the mixture was measured at $415 \mathrm{~nm}$ in a microplate reader (PowerWave $\times$ TM). The flavonoid content was expressed as mg QE/g dry weight of AFMF.

Ultra Performance Liquid Chromatography (UPLC). The ultra performance liquid chromatography (UPLC) technique was adopted to elucidate the possible phytochemical(s) in AFMF. AFMF was dissolved in HPLC methanol at $1 \mathrm{mg} / \mathrm{ml}$, while quercetin and rutin (standards) were prepared separately first, and then the mixture of the two standards was at $0.1 \mathrm{mg} / \mathrm{ml}$. The solutions of AFMF and the standards were separately passed through a syringe filter $(0.22 \mu \mathrm{m})$ into $2.0 \mathrm{ml} \mathrm{Vi-}$ als, and covered. Chromatography was carried out with an Acquity-UPLC ${ }^{\text {TM }}$ system (Waters, MA, USA) in which the separation of AFMF and standards was performed by reversed phase (RP) chromatography, using BEH C18 column (Waters) with $100 \mathrm{~mm} \times 2.1 \times 1.7 \mu \mathrm{m}$ of particle size. The mobile phases; 'A' consisted of $0.1 \%$ formic acid in deionized water while ' $\mathrm{B}$ ' had $0.1 \%$ formic acid in acetonitrile, and were used for the analysis at $60 \%$ (A) to $40 \%$ (B) proportions. The injected volume was $3 \mu \mathrm{L}$ at $0.1 \mathrm{~mL} /$ minute flow rate. The separation was held for 10 minutes while compounds were detected by a photodiode array (PDA) detector at $280 \mathrm{~nm}$ (Dartora et al., 2011). The retention time for the separation of AFMF was compared with that of rutin and quercetin antimutagenic standards.

The quantity of the suspected antimutagenic compound in AFMF was determined by preparing $0.1 \mathrm{mg} /$ $\mathrm{ml}$ of pure rutin compound and diluted by two folds to obtain lower concentrations. The chromatographic separation of rutin and AFMF followed the method (Dartora et al., 2011). The areas under the peaks of chromatograms of rutin were plotted against concentrations. The quantity of rutin in $1 \mathrm{mg}$ of AFMF was obtained from the graph.

\section{RESULTS}

The induction of base pair substitution mutation in $S$. typhimurium TA100 strain was not concentration dependent (Fig. 1). The highest and least mutagenicity ratio of 1.71 and 1.21 were observed at $200 \mu \mathrm{g} /$ well and 500 $\mu \mathrm{g} /$ well, respectively. The mutagenic activity of benzo[a] pyrene was suppressed above $50 \%$ at the tested concentrations, with the highest inhibition percentage of $87 \%$ recorded at 4 and $50 \mu \mathrm{g} /$ well concentrations. However, the suppression of mutagenicity of benzo[a]pyrene at 20, 100,200 , and $1000 \mu \mathrm{g} /$ well was less, indicating non concentration-dependent inhibition of the mutagenic action of benzo[a]pyrene by AFMF (Fig. 2).

The clastogenic effects of AFMF on bone marrow cells of the treated mice are presented in Table 1 . There was induction of micronucleated polychromatic erythrocytes (MNPCE) in a non-concentration dependent manner. The induced micronucleated normochromatic erythrocyte (MNNCE) at $500 \mathrm{mg} / \mathrm{kg}$ was higher than that recorded with the negative control. However, there was

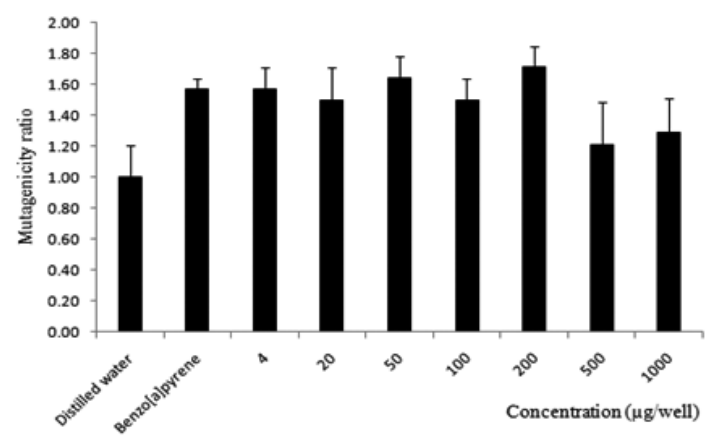

Figure 1. Mutagenic activity of aqueous fraction of $M$. fragrans with metabolic activation in S. typhimurium TA100.

Error bars represent standard deviation of average number of re-

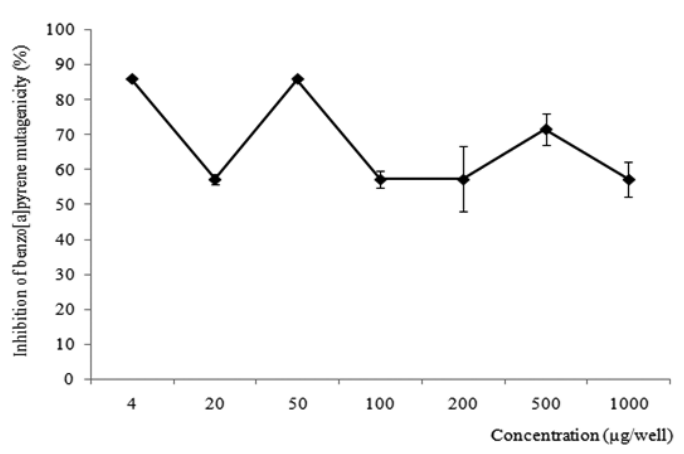

Figure 2. Supression of benzo[a]pyrene-induced mutagenicity in S. typhimurium TA100 by aqueous fraction of $M$. fragrans. Error bars represent standard deviation of mutagenicity inhibition $(n=3)$ 
Table 1. Clastogenic and proliferative effects of aqueous fraction of M. fragrans on bone marrow cells in Swiss albino mice

\begin{tabular}{lcccc}
\hline Concentration $(\mathrm{mg} / \mathrm{kg})$ & MNPCE \pm S.D. & MNNCE \pm S.D. & $\%$ PCE & $\%$ NCE \\
\hline Distilled water & $0.83 \pm 0.75^{\mathrm{a}}$ & $0.17 \pm 0.14^{\mathrm{a}}$ & 83.83 & 16.17 \\
\hline 500 & $1.83 \pm 1.72^{\mathrm{a}}$ & $0.33 \pm 0.52^{\mathrm{a}}$ & 85.00 & 15.00 \\
\hdashline 1000 & $1.17 \pm 1.47^{\mathrm{a}}$ & $0.00 \pm 0.00^{\mathrm{a}}$ & 85.33 & 14.67 \\
\hline 2000 & $2.00 \pm 1.90^{\mathrm{a}}$ & $0.00 \pm 0.00^{\mathrm{a}}$ & 80.83 & 19.67 \\
\hdashline 4000 & $2.17 \pm 1.72^{\mathrm{a}}$ & $0.00 \pm 0.00^{\mathrm{a}}$ & 73.00 & 27.00 \\
\hline
\end{tabular}

Values with same letter in superscript are not significantly different $(\mathrm{p} \leq 0.05)$, MNPCE, micronucleated polychromatic erythrocyte; SD, standard deviation; MNNCE, micronucleated normochromatic erythrocyte; PCE, polychromatic erythrocyte; NCE, normochromatic erythrocyte

Table 2. Antimutagenic activity of aqueous fraction of $M$. fragrans against CP-induced micronucleated erythrocytes in mouse bone marrow cells

\begin{tabular}{lccccc}
\hline Concentration $(\mathrm{mg} / \mathrm{kg})$ & MNPCE \pm S.D. & MNNCE \pm S.D. & $\%$ PCE & $\%$ NCE & Reduction of MN (\%) \\
\hline Distilled water & $0.50 \pm 0.55$ & $0.17 \pm 0.41$ & 88.00 & 12.00 & - \\
\hline CP & $4.17 \pm 2.48^{*}$ & $1.17 \pm 1.47$ & 81.83 & 18.17 & - \\
\hline 500 & $2.80 \pm 2.14$ & $0.17 \pm 0.41$ & 82.33 & 17.67 & 50.75 \\
\hline 1000 & $2.50 \pm 2.59$ & $0.00 \pm 0.00$ & 82.33 & 17.17 & 60.81 \\
\hline 2000 & $4.00 \pm 2.45^{*}$ & $0.83 \pm 0.75$ & 77.67 & 22.33 & 10.92 \\
\hline 4000 & $2.83 \pm 1.94$ & $0.17 \pm 0.41$ & 78.83 & 21.17 & 50.11 \\
\hline
\end{tabular}

*Values are significantly different from negative control $(p \leq 0.05)$. MNPCE, micronucleated polychromatic erythrocyte; S.D., standard deviation, MNNCE, micronucleated normochromatic erythrocyte; PCE, polychromatic erythrocyte; NCE, normochromatic erythrocyte; MN, micronucleus

Table 3. DPPH scavenging activity, total phenolic and flavonoid contents of aqueous fraction of M. fragrans

\begin{tabular}{llll}
\hline Sample & $\begin{array}{l}\text { DPPH scaven- } \\
\text { ging power } \\
\left(\mathrm{IC}_{50}\right) \mathrm{mg} / \mathrm{ml}\end{array}$ & $\begin{array}{l}\text { Total pheno- } \\
\text { lic contents } \\
(\mathrm{mgGAE} / \mathrm{g})\end{array}$ & $\begin{array}{l}\text { Flavonoid } \\
\text { contents } \\
(\mathrm{mgQE} / \mathrm{g})\end{array}$ \\
\hline $\begin{array}{l}\text { Aqueous extract } \\
\text { fraction }\end{array}$ & 0.11 & 51.00 & 27.00 \\
\hdashline BHA & 0.02 & - & - \\
\hline BHT & 0.04 & - & - \\
\hline
\end{tabular}

DPPH, 2,2-diphenyl-1-picrylhydrazyl; BHA, butylated hydroxylanisole; $\mathrm{BHT}$, butylated hydroxyltoluene; $\mathrm{IC}_{50}, 50 \%$ Inhibitory concentration; mgGAE: miligram of Gallic acid equivalent; mgQE: miligram of Quercetin equivalent.

no significant difference between the MNPCE and MN$\mathrm{NCE}$ induced at the tested concentrations and negative control $(p>0.05)$. The proliferation of bone marrow cells was not significantly suppressed. However, the mutagenic activity of $\mathrm{CP}$ in inducing micronucleated erythrocytes (MNPCE and MNNCE) was suppressed throughout the tested concentrations. The highest inhibition of mutagenic effect of CP was $60.81 \%$, recorded at $1000 \mathrm{mg} /$ $\mathrm{kg}$ while the least inhibition of $10.92 \%$ was recorded at $2000 \mathrm{mg} / \mathrm{kg}$ (Table 2).

The DPPH free radical scavenging power, total phenolic and flavonoid contents of AFMF are presented in Table 3. Butylated hydroxyl anisole (BHA) and butylated hydroxyl toluene (BHT) were more powerful than AFMF. The $\mathrm{IC}_{50}$ values obtained for AFMF, BHA and BHT were $0.11 \mathrm{mg} / \mathrm{ml}, 0.02$ and $0.04 \mathrm{mg} / \mathrm{ml}$, respectively. Total phenolic content of $51.0 \mathrm{mg}$ GAE/g was observed in AFMF, while the flavonoid content was 27.0 $\mathrm{mg} \mathrm{QE} / \mathrm{g}$.

The results of ultra performance liquid chromatographic separation of AFMF and the two standards

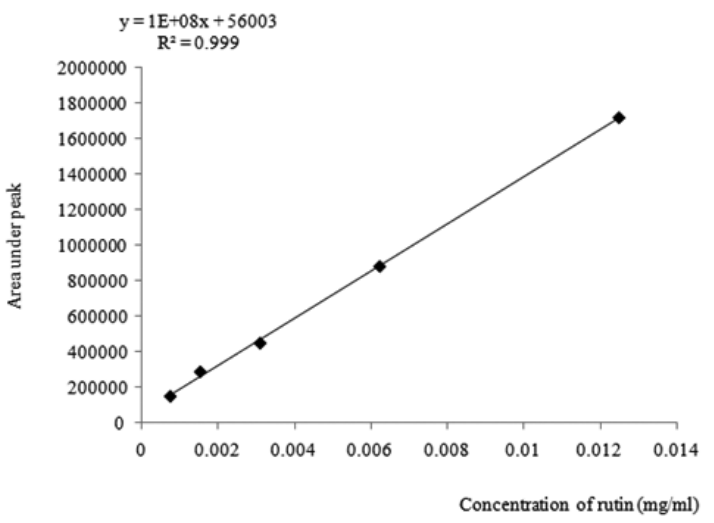

Figure 3. Quantification of rutin in the aqueous fraction of $M$. fragrans using UPLC analysis

(quercetin and rutin) are presented in Table 4. The retention times of 2.841, and 4.325 minutes were respectively recorded for the separation of the mixture of rutin and quercetin. However, AFMF and the control standard (rutin) had almost similar retention times of 2.09 \& 2.837 minutes, and $2.109 \& 2.841$ minutes, respectively. The quantity of rutin obtainable in $1 \mathrm{~g}$ of AFMF was estimated to be $9.0 \mathrm{mg}$ (Fig. 3).

\section{DISCUSSION}

The Ultra Performance Liquid Chromatographic separation of AFMF suggested inclusion of rutin, as evident in similar retention times obtained for the rutin standard and AFMF under the same conditions. The induction of revertants of $S$. typhimurium by AFMF in a nonconcentration dependent manner, and obtainment of mutagenicity ratio $R<2$ at all the tested concentrations 
Table 4. Chromatographic characteristics of aqueous fraction of $M$. fragrans and two antioxidant standards (quercetin and rutin)

\begin{tabular}{|c|c|c|c|c|c|}
\hline Sample & Peak & Retention time (mins) & Area & $\%$ Area & Height \\
\hline \multirow{2}{*}{$\begin{array}{l}\text { Aqueous } \\
\text { fraction }\end{array}$} & 1 & 2.09 & 39618906 & 72.24 & 2715508 \\
\hline & 2 & 2.84 & 15224158 & 27.76 & 2383789 \\
\hline \multirow{3}{*}{$\begin{array}{l}\text { Mixture of quercetin } \\
\text { and rutin }\end{array}$} & 1 & 2.15 & 16245542 & 22.31 & 910195 \\
\hline & 2 & 2.84 & 20966184 & 28.80 & 2828805 \\
\hline & 3 & 4.33 & 35592891 & 48.89 & 2770847 \\
\hline Quercetin alone & 1 & 4.321 & 31308527 & 100.00 & 2587250 \\
\hline \multirow{2}{*}{ Rutin alone } & 1 & 2.11 & 6822785 & 39.19 & 484356 \\
\hline & 2 & 2.84 & 10585689 & 60.81 & 1831980 \\
\hline
\end{tabular}

suggest non-mutagenic potential of AFMF. A chemical substance is considered mutagenic in $S$. typhimurium tester strain TA100 if it produces a concentration dependent mutagenicity ratio $R \geq 2$ (Flamand et al., 2001). This was corroborated by the results of the bone marrow micronucleus test in this study. The presence of rutin as the major phytochemical in the AFMF explains its non- mutagenic behavior. Rutin and its metabolites were reported to be non-mutagenic in $S$. typhimurium tester strains (BenRhouma et al., 2012). It neither diminished cell viability nor reduced cell proliferation in the hepatic cells, and was not genotoxic in mice (Hardigree and Epler, 1978; da Silva et al., 2002; Cristina-Marcarini et al., 2011). This was attributed to the existence of rutin in a glycosylated form which is probably not absorbed directly in the cell (Manach et al., 1987). The absorption of rutin depends on the action of glycosidases, hydrolyzing rutin to aglycone quercetin which may not be absorbed before being further degraded to non-mutagenic aromatic acids and carbon dioxide (Crebelli et al., 1987).

The results of DPPH free radical scavenging activity of BHA and BHT which were higher than that recorded for AFMF were contrary to our previous data on the DPPH free radical scavenging activity of methanol extract of $M$. fragrans (Akinboro et al., 2012). This may be due to lack of a synergistic interaction in AFMF as might have been the case with methanol extract of $M$. fragrans. The antioxidant activity of rutin using different assays has been reported with obtainment of strong DPPH radical scavenging activity (Yang et al., 2008). Natural flavonoids scavenge free oxygen and nitrogen radicals effectively in vivo and in vitro, perhaps because of their ability to act as hydrogen or electron donors (Lue et al., 2010).

The antimutagenic effects of AFMF on Salmonella typhimurium TA100 showed strong inhibition of B[a]Pinduced mutagenicity at all tested concentrations. Our results corroborated the reported antimutagenic activity of the major flavonoids of rooibos (Aspalathus linearis) in the $S$. typhimurium mutagenicity assay employing TA98 and TA100 tester strains (Snijman et al., 2007). In their experiment, rutin showed antimutagenic activity against 2-acetamido-fluroene (2AAF) and aflatoxin $\mathrm{B}_{1}\left(\mathrm{AFB}_{1}\right)$ in a non- concentration dependent manner. In the present study, the suppression of CP-induced mutagenicity in the in vivo tests further confirmed the observed antimutagenic activity in the in vitro model. The suppression of mutagen-induced mutations in the target cells of $S$. typhimurium and $M$. musculus was non-dose dependent. The lack of dose-dependent suppression of mutagenic action of the two pro-mutagens by AFMF could be the result of activation of different metabolic pathways in the test organisms. Similar antimutagenic activity of rosmarinic acid and rutin was observed in Swiss albino mice and human lymphocytes in a non-dose dependent manner (Furtado et al., 2008; Undeger et al., 2004).

To the best of our knowledge, this is the first time that the antimutagenic activity of AFMF, suspected to have been brought about by rutin, was reported in S. typhimurium TA100 tester strain and in Swiss albino mice. Previous studies showed that mace lignans from $M$. fragrans significantly inhibited radiation-induced DNA damages in skin keratinocyes and splenocytes (Checker et al., 2008; Anggakusuma et al., 2010). Benzo[a]pyrene and cyclophosphamide are pro-mutagens which produce active electrophilic metabolites that are the main inducers of DNA or chromosomal damage (Boyd et al., 1986; Ueng et al., 2001). It has been reported that rutin protects DNA from the action of mutagens/carcinogens by modulating the enzymes necessary for activation of carcinogens or inhibiting the activation of mutagens (Mallet et al., 1989; Webster et al., 1996). Thus, alteration in the metabolic pathways of $\mathrm{B}[\mathrm{a}] \mathrm{P}$ and $\mathrm{CP}$ is expected to have prevented these pro-mutagens from being converted to their mutagenic metabolites in the test organisms. The free radical scavenging effects of the AFMF could be due to its phenolics which are capable of donating hydrogen atoms or electrons to the electrophilic mutagenic metabolites of $\mathrm{B}[\mathrm{a}] \mathrm{P}$ and $\mathrm{CP}$ in order to make them stable and nonreactive with DNA, hence, suppression of their mutagenicity.

Rutin and its aglycone quercetin have been reported to be effective in inhibiting lipid peroxidation, the action that is possible through the scavenging of free radicals, and consequently prevents damage to DNA. Other possible mechanisms of antimutagenic actions of flavonoids such as carcinogen inactivators, inhibitors of tumor cell growth, modulators of DNA repair, or inducers of apoptosis cannot be completely ruled out. Polyphenols are an important group of pharmacologically active compounds which are most often found with remarkable antioxidant activities (Boubaker et al., 2010). Rutin, a polyphenolic compound, has been shown to possess anticarcinogenic activity against a variety of chemicals, and other healing properties such as antimutagenic, anti-inflammatory, antidiarrhoea, myocardial protector and immuno-modulator (Webster et al., 1996; Arjumand et al., 2011). It is interesting that in the two assays reported here, the best antimutagenic activity of the AFMF was observed at the lower doses. The lower doses of AFMF in this study might have behaved as DPPH free radical scavengers (antioxidants) capable of suppressing the induction of genetic mutations caused by the two mutagens, hence, the obtainment of higher reduction percentages of $\mathrm{B}[\mathrm{a}]$ 
$\mathrm{P}$ and CP-induced mutations. However, the lower reduction percentages of $\mathrm{B}[\mathrm{a}] \mathrm{P}$ and $\mathrm{CP}$-induced mutagenicity obtained at higher doses could have resulted from prooxidant activity of AFMF thereby causing oxidative-redox cycle to induce DNA damage.

The small amount of rutin in AFMF confirmed its strong antimutagenic activity, as suggested by the inhibition of $\mathrm{B}[\mathrm{a}] \mathrm{P}$ and $\mathrm{CP}$-induced mutations above $50 \%$ at the lowest concentration of $4 \mu \mathrm{g} /$ well and $500 \mathrm{mg} / \mathrm{kg}$ in the in vitro and in vivo assays, respectively.

\section{CONCLUSION}

This study revealed that AFMF possessed strong antimutagenic activity in the selected genetic assays, without being significantly mutagenic. The free radical scavenging activity of AFMF, suspected to have been brought about by the rutin phytochemical, could be responsible for the observed antimutagenicity in the in vitro and in vivo tests. Therefore, the results obtained in this study suggest that AFMF is a promising therapeutic agent in the development of anticancer chemotherapeutics.

\section{Acknowledgements}

This research work was materially and financially supported by the Universiti Sains Malaysia and The World Academy of Sciences under the USM-TWAS postgraduate fellowship scheme. The short term grant and the study leave with pay enjoyed by Dr. Akeem Akinboro from the management of Ladoke Akintola University of Technology (LAUTECH), Ogbomoso, Nigeria, are much appreciated.

\section{REFERENCES}

Akinboro A, Mohamed KB, Asmawi MZ, Sofiman OA (2011a) Mutagenic and antimutagenic potentials of fruit juices of five medicinal plants in Allium cepa L.: Possible influence of DPPH free radical scavengers. Afr J Biotechnol 10: 10520-10529.

Akinboro A, Mohamed KB, Asmawi MZ, Sulaiman SF, Sofiman OA (2011b) Antioxidants in aqueous extract of Myristica fragrans (Houtt.) suppress mitosis and cyclophosphamide-induced chromosomal aberrations in Allium cepa L. cells J Zhejiang Univ Sci B (Biomedicine \& Biotechnology) 12: 915-922.

Akinboro A, Mohamed KB, Asmawi MZ, Sofiman OA, Ying TH, Maidin SM (2012) Mutagenic and antimutagenic assessment of methanol leaf extract of Myristica fragrans (Houtt.) using in vitro and in vivo genetic assays Drug Chem Toxicol 35: 412-422.

Anggakusuma Y, Jae-kwan H (2010) Effects of macelignan isolated from Myristica fragrans Houtt. On UVB-induced matrix metalloproteinase- 9 and cyclooxygenase- 2 in HacaT cells, J Dermatol Sci 57: $114-122$

Arjumand W, Seth A, Sultana S (2011) Rutin attenuates cisplatin induced renal inflammation and apoptosis by reducing NF B, TNFand caspase-3 expression in wistar rats. Food and Chem Toxicol 49: 2013-2021.

Ben Rhouma G, Chebil L, Krifa M, Ghoul M, Chekir-Ghedira L (2012) Evaluation of mutagenic and antimutagenic activities of oligorutin and oligoesculin. Food Chem 135: 1700-1707.

Boubaker J, Skandrani I, Bouhlel I, Ben Sghaier M, Neffati A, Ghedira K, Chekir-Chedira L (2010) Mutagenic, antimutagenic and antioxidant potency of leaf extract of from Nitraria retusa. Food Chem Toxicol 48: 2283-2290.

Boyd RD, Baumaa DE, Berman DH, DeNeergard AP, Souza L, Butler WR (1986) Titration of the porcine growth hormone dose which maxmizes growth performance and lean deposition in swine. J Anim Sci 63 (Suppl): 1218.

Chatterjee S, Zareena N, Gautam S, Soumyakanti A, Prasad SV, Arun S (2007) Antioxidant activity of some phenolic constituents from green pepper (Piper nigrum L.) and fresh nutmeg mace (Myristica fragrans). Food Chem 101: 515-523.

Checker R, Chatterjee S, Sharma D, Gupta S, Variyar P, Sharma A, Poduval TB (2008) Immunomodulatory and radioprotective effects of lignans derived from fresh nutmeg mace (Myristica fragrans) in mammalian splenocytes. Int Immunopharmaco 8: 661-669.
Crebelli R, Aquilla E, Falcone A, Carere A (1987) Urinary and faecal mutagenicity in Sprague-Dawley rats dosed with the food mutagens quercetin and rutin. Food Chem Toxicol 25: 9-15.

Cristina Marcarini J, Ferreira Tsuboy MS, Cabral Luiz R, Regina Ribeiro L, Hoffmann-Campo CB, Ségio Mantovani M (2011) Investigation of cytotoxic, apoptosis-inducing, genotoxic and protective effects of the flavonoid rutin in HTC hepatic cells. Exp Toxicol Pathol 63: 459-465.

da Silva J, Herrmann SM, Heuser V, Peres W, Marroni NP, Gallego JG, Erdtmann B. (2002) Evaluation of the genotoxic effect of rutin and quercetin by comet assay and micronucleus test. Food Chem Toxicol 40: 941-947.

Dartora N, de Souza LM, Santana-Filho AP, Iacomini M, Valduga AT, Gorin PAJ, Sassaki GL (2011) UPLC-PDA-MS evaluation of bioactive compounds from leaves of Ilex paraguariensis with different growth conditions, treatments and ageing. Food Chem 129: 14531461 .

Ferguson LR, Denny WA, Boritzki TJ (1994) DNA-directed aniline mustards with high selectivity for adenine or guanine bases: mutagenesis in a variety of Salmonella typhimurium strains differing in repair-capability. Mutat Res 331: 1-26.

Flamand N, Meunier JR, Meunier PA, Agapakis-Caussé C (2001) Mini mutagenicity test: a miniaturized version of the Ames test used in a prescreening assay for point mutagenesis assessment. Toxicol in Vitro 15: 105-114.

Furtado MA, Fernandes DE, Almeida LC, Furtado RA, Cunha WR, Tavares DC (2008) Antimutagenicity of rosmarinic acid in Swiss mice evaluated by the micronucleus assay. Mutat Res 657: 150-154.

Gülçin I (2009) Antioxidant activity of L-adrenaline: A structure-activity insight. Chem Biol Interact 179: 71-80.

Ham SS, Kim SH, Moon SY, Chung MJ, Cui CB, Han EK, Chung CK, Choe M (2009) Antimutagenic effects of subfractions of Chaga mushroom (inonotus obliquus) extract. Mutat Res 672: 55-59.

Hardigree AA, Epler LL (1978) Comparative mutagenesis of plant flavonoids in microbialsystems. Mutat Res 58: 231-239.

Jayaprakasha GK, Negi PS, Jena BS, Rao JM (2007) Antioxidant and antimutagenic activities of Cinnamomum zeylanicum fruit extracts. J Food Compos Anal 20: 330-336.

Krishna G, Hayashi M (2000) In vivo rodent micronucleus assay: protocol, conduct and data interpretation. Mutat Res 455: 155-166.

Loh YDS, Meng H, Chen YS (2009) Mutagenic and antimutagenic activities of aqueous and methanol extracts of Euphorbia hirta. I Ethnopharmacol 126: 406-414.

Lue BM, Nielsen NS, Jacobsen C, Hellgren L Guo Z, Xu X (2010) Antioxidant properties of modified rutin esters by DPPH reducing power, iron chelation and human low density lipoprotein assays. Food Chem 123: 221-230.

Mallett AK, Bearne CA, Rowland IR (1989) The influence of incubation $\mathrm{pH}$ on the activity of rat and human gut flora enzymes. $J$ Appl Bacteriol 66: 433-437.

Manach L, Morand C, Texier O, Favier ML, Agullo G, Demigne C, Regerat F, Remesy C (1995). Quercetin metabolites in plasma of rats fed diets containing rutin or quercetin. I Nutr 125: 1911-1922.

Mortelmans K, and Zeiger E (2000). The Ames Salmonella/microsome mutagenicity assay. Mutat Res 455: 29-60.

Negi PS, Jayaprakasha GK, Jena BS (2003) Antioxidant and antimutagenic activities of pomegranate peel extracts Food Chem 80: 393-397.

Nguyen PH, Thu Le TV, Kang HW, Chae J, Kim SK, Kwon KI, Seo DB, Lee SJ, Oh WK (2010) AMP-activated protein kinase (AMPK) activators from Myristica fragrans (nutmeg) and their anti-obesity effect. Bioorg Med Chem Lett 20: 4128-4131.

Organization for Economic Cooperation and Development (1997) Bacteria Reverse Mutation Test, Guideline for testing of chemicals, Adopted 21st July, 1997.

Oh HT, Kim SH, Choi HJ, Chung MJ, Ham SS (2008) Antioxidative and antimutagenic activities of $70 \%$ ethanol extract from masou salmon (Oncorbynchus masou). Toxicol In Vitro 22: 1484-1488.

Piaru SP, Mahmud R, Abdul Majid AMS, Ismail S, Man CN (2011) Chemical composition, antioxidant and cytotoxicity activities of the essential oils of Myristica fragrans and Morinda citrifolia. I Sci Food Agric (Published online in Wiley Online Library), 4613.

Rosidah, Yam MF, Amirin S, Mohd Zaini A (2008) Antioxidant potential of Gynura procumbes. Pharma Biol 46: 616-625.

Sherwin CM (2006) Guideline for the treatment of animals in behavioral research and teaching. Anim Behav 71: 245-253.

Snijman PW, Swanevelder S, Joubert E, Green IR, Gelderblom WCA (2007) The antimutagenic activity of the major flavonoids of rooibos (Aspalathus linearis): Some dose-response effects on mutagen activation-flavonoid interactions. Mutat Res 631: 111-123.

Su L, Yin JJ, Charles D, Zhou K, Moore J, Yu L. (Lucy) (2007) Total phenolic contents, chelating capacities and radical-scavenging properties of black peppercorn, nutmeg, rosehip, cinnamon and oregano leaf. Food Chem 100: 990-997.

Sulaiman SF, Sajak AAB, Ooi KL, Supriatno, Seow EM (2011) Effect of solvents in extracting polyphenols and antioxidants of selected raw vegetables. J Food Compos Anal 24: 506-515. 
Sulaiman SF, and Ooi KL (2012) Antioxidant and anti food-borne bacterial activities of extracts from leaf and different fruit parts of Myristica fragrans Houtt. Food Control 25: 533-536.

Ueng YF, Shyu CC, Liu TY, Oda Y, Lin YL, Liao JF, Chen CF (2001)

Protective effects of baicalein and wogonin against benzo[a]pyreneand aflatoxin $\mathrm{B}_{1}$-induced genotoxicities. Biochem Pharmacol 62: 16531660.

Ündeğer Ü, Aydin S, Başaran AA, Başaran N (2004) The modulating effects of quercetin and rutin on the mitomycin $\mathrm{C}$ induced DNA damage. Toxicol Lett 151: 143-149.
Webster RP, Gawde MD, Bhattacharya RK (1996) Protective effect of rutin, a flavonol glycoside, on the carcinogen-induced DNA damage and repair enzymes in rats. Cancer Lett 109: 185-191.

William PJ, Douglas K (2005) Extraction of plant secondary metabolites. In: Natural Products Isolation, Methods Biotechnol 20: 323-351. Yang J, Guo J, Yuan J. (2008) In vitro antioxidant properties of rutin. LWT 41: 1060-1066. 